\title{
Pacifier-sucking habit duration and frequency on occlusal and myofunctional alterations in preschool children
}

\section{Valdeane Simone Cenci NIHI(a) Sandra Mara MACIEL(b) \\ Marta Essuane JARRUS(c) \\ Fábio Mitugui NIHI(a) \\ Carlos Luiz Fernando de SALLES(b) \\ Renata Corrêa PASCOTTO(b) \\ Mitsue FUJIMAKI (b)}

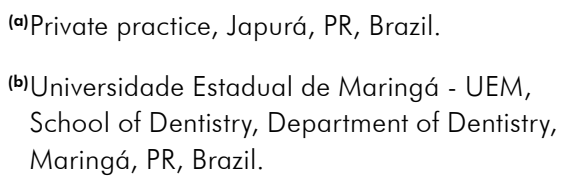

Declaration of Interests: The authors certify that they have no commercial or associative interest that represents a conflict of interest in connection with the manuscript.

Corresponding Author:

Mitsue Fujimaki

E-mail:mfujimaki@uem.br

DOI: 10.1590/1807-3107BOR-2015.vol29.0013

Submitted: Mar 25, 2014

Accepted for publication: Aug 13, 2014

Last revision: Nov 04, 2014

\begin{abstract}
The objective of this study was to evaluate the association of pacifier-sucking habit with occlusal and oral myofunctional alterations in preschool children. Eighty-four 2- to 5-year-old children participated in the study. Data on duration and frequency of pacifier use were collected from parents or guardians. Occlusal and oral myofunctional characteristics were examined by a dentist and a speech therapist, respectively. Chi-square tests and Poisson regression were used to analyze the data. The occlusal characteristics that were significantly associated with a pacifier-sucking habit were anterior open bite, altered canine relation, posterior crossbite, increased overjet, and malocclusion. The oral myofunctional characteristics that were significantly associated with a pacifier-sucking habit were resting lip position, resting tongue position, shape of the hard palate, and swallowing pattern. The strongest associations were for anterior open bite (prevalence ratio $[P R]=11.33$ ), malocclusion ( $P R=2.33)$, altered shape of the hard palate $(P R=1.29)$, and altered swallowing pattern $(P R=1.27)$. Both duration and frequency of pacifier-sucking habit were associated with occlusal and oral myofunctional alterations. These results emphasize the need for pediatric dentists to advise parents and caregivers about the risks of prolonged pacifier use and refer children to professionals for multidisciplinary assistance to minimize these risks whenever necessary.
\end{abstract}

Keywords: Pacifier; Malocclusion; Stomatognathic System.

\section{Introduction}

Pacifier sucking is a common non-nutritive habit in several parts of the world. In Western countries, pacifiers are used by $75-95 \%$ of the infant population during the first 2 years of the child's life. ${ }^{1,2,3,4}$ The use of pacifiers is so culturally established that they have even been integrated into layettes. ${ }^{5}$ Parents frequently appease crying babies with pacifiers. However, the prolonged use of pacifiers can be harmful to a child's development, affecting occlusion and the stomatognathic system. ${ }^{6}$

Several studies have reported the influence of non-nutritive sucking habits on the development of dental malocclusion. 2,3,6,7,8,9,10,11,12,13 They highlight the consequences of prolonged daily use of pacifiers on children's orofacial health, with 48 months of pacifier use needed for the onset of malocclusion. ${ }^{1}$ Malocclusion can have an important impact on the life quality of children, negatively affecting their social interactions and psychological well-being. ${ }^{11}$ 
However, the prevalence of some changes in occlusion, such as anterior open bite, may decrease with age, indicating that malocclusion has the potential to selfcorrect with elimination of the stimulus, particularly if the sucking habit is discontinued at around 2 to 3 years of age. ${ }^{9,14,15}$ Hence, it is important to increase our understanding of the association of prolonged pacifier use with alterations in occlusion and oral myofunction in preschool children who are being introduced to oral health care. This would provide pediatric dentists with clinical evidence to guide the children's parents and guardians.

Therefore, the aim of the present study was to evaluate the association of the duration and frequency of a pacifiersucking habit with occlusal and oral myofunctional alterations in a group of preschool children.

\section{Methodology}

This cross-sectional study was conducted on a convenience sample of preschool children enrolled at an Early Childhood Education Centre located in a highsocial-risk area in the municipality of Maringá, Brazil. The initial sample consisted of 104 preschool children with complete primary dentition. Children presenting any of the following characteristics were excluded from the study: general health problems that prevented clinical examination, finger sucking, extensive caries affecting the vertical dimension and/or the mesiodistal diameter of teeth, and the presence of permanent teeth. Children who did not cooperate with the study procedures were also excluded. All study procedures were approved by the Universidade Estadual de Maringá - Ethics Committee on Research with Human Subjects (Protocol CAAE no. 0482.0.093.000-10).

The objective of the study was fully explained to children's caregivers (parents or legal guardians), and written informed consent was obtained. Caregivers were then asked about their child's use of pacifiers. Duration of use was classified as never, $\leq 2$ years, $>2$ and $\leq 3$ years, or $>3$ years. Frequency of use was classified as limited (pacifier used only for sleeping), moderate (pacifier used intermittently for $\leq 8$ hours during the day), or intense (pacifier used continuously throughout the day and night). ${ }^{16,17}$

Clinical examinations were conducted at the school under natural lighting by two examiners: a pediatric dentist (VSCN) and a speech therapist (MEJ). Examinations included evaluations of dental occlusion and oral myofunction. Examiner calibration was conducted in a pilot study performed with 30 randomly chosen children. Two examinations separated by an interval of 10 days were performed for each child. Intra-examiner reliability for all variables was evaluated using the kappa statistic.

Dental occlusion was evaluated when the child was seated in front of the examiner. To ensure that natural occlusion was evaluated, the child was asked to open and close his/her mouth several times and to swallow saliva before the examination began. ${ }^{16,17}$ The following characteristics were evaluated during the examination: (i) anterior open bite, ${ }^{16,17}$ (ii) anterior crossbite, ${ }^{10}$ (iii) overjet ${ }^{1,7,16,18}$ (iv) midline deviation, (v) overbite, ${ }^{19}$ (vi) canine relation, ${ }^{7,12}$ (vii) intercanine distance, ${ }^{16,17}$ (viii) posterior crossbite, ${ }^{7}$ and (ix) malocclusion. Overjet was measured using an endodontic millimeter ruler and classified as increased if $>3 \mathrm{~mm}$. Midline deviation was assessed with a piece of dental floss placed on the midline of the child's face, and intercanine distance was measured using a bow compass. Overbite was classified as $\leq 50 \%$ or $>50 \%$ of the crown size, with $\leq 50 \%$ considered normal and $>50 \%$ considered altered. Canine relation was classified as class I, II, or III, with class I considered normal and classes II and III considered altered. Malocclusion was defined as the presence of at least one occlusal change, such as anterior open bite, altered intercanine relation, posterior crossbite, or increased overjet.

Oral myofunction was intra- and extra-orally evaluated. The following characteristics were noted and classified as normal or altered: (i) lip position at rest - fully closed (normal) or partially closed (altered);:20 (ii) lip closure - without tension (normal) or with tension (altered) ${ }_{r}^{20}$ (iii) tongue position at rest - touching the palate (normal), resting on the floor of the mouth (altered), or interposed between the arches (altered); ${ }^{21}$ (iv) lingual frenulum - normal or short, ${ }^{14,20}$ (v) cheek symmetry - symmetric (normal) or asymmetric (altered), ${ }_{i}^{16}$ (vi) shape of the hard palate - semi-circular (normal), ogival (altered), or deep (altered),16 (vii) breathing at rest - predominantly nasal (normal), predominantly oral (altered), or mixed; ${ }^{21}$ (viii) nasal flow -present (normal) or absent 
(altered), ${ }^{21}$ (ix) swallowing pattern -no tension on the lips and perioral muscles and no tongue protrusion (normal), atypical (altered), or adapted (altered); (x) chewing pattern - predominantly bilateral (normal) or predominantly unilateral (altered); and (xi) speech - considered altered in the presence of anterior or lateral tongue protrusion or speech delay. ${ }^{16}$ Breathing at rest was evaluated with a Glatzel mirror and nasal flow was evaluated with a Glatzel mirror placed near the nostrils when the child was instructed to breath through the nose. Swallowing pattern was evaluated when the child was eating a chocolate biscuit, and chewing pattern was evaluated using the marks left by the biscuit on dental and lingual aspects. Speech was evaluated when the child produced Portuguese words with the phonemes $/ \mathrm{t}, \mathrm{d}, \mathrm{n}, \mathrm{l}, \mathrm{s}, \mathrm{z} /{ }^{1}$

Preliminary bivariate analyses (chi-square test) were run to identify occlusion and oral myofunction variables that were significantly associated with pacifier use. These variables were entered into a Poisson regression to predict the likelihood of alterations according to the duration and frequency of pacifier use. In addition, the intercanine distance was compared between children with and without a pacifier-sucking habit using a t-test for independent samples. All statistical analyses were performed using SPSS 15.0 (SPSS Inc., Chicago, USA) with the alpha level set at 0.05 .

\section{Results}

The final sample consisted of 84 children between 2 and 5 years of age (mean age $42 \pm 11$ months) with a predominance of males (61.9\%). Data on gender and age distribution and on the duration and frequency of pacifier use are presented in Table 1.

The mean intra-examiner correlation coefficient (kappa statistic) was 0.96 for dental occlusion variables and 0.89 for oral myofunction variables. The prevalence of occlusal and myofunctional alterations in children with and without a pacifier-sucking habit are presented in Table 2. Chi-square analysis showed that the occlusal alterations significantly associated with a pacifiersucking habit were anterior open bite, altered intercanine relation, posterior crossbite, increased overjet, and malocclusion. The myofunctional alterations significantly associated with a pacifier-sucking habit were a partially closed lip position at rest, lip closure with tension,
Table 1. Participant characteristics.

\begin{tabular}{lc}
\hline Characteristic & $\mathrm{n}(\%)$ \\
\hline Gender & $52(61.9)$ \\
Male & \\
Female & $32(38.1)$ \\
Age & \\
2 years & $12(14.3)$ \\
3 years & $30(35.7)$ \\
4 years & $33(39.3)$ \\
5 years & $9(10.7)$ \\
Duration of pacifier use* & \\
Never & $48(57.1)$ \\
$\leq 2$ years & $11(13.1)$ \\
$>2$ and $\leq 3$ years & $9(10.7)$ \\
$>3$ years & $15(17.9)$ \\
Frequency of pacifier use & \\
Never & $48(57.1)$ \\
Limited use (night only) & $13(15.5)$ \\
Moderate use (> 8 h per day) & $12(14.3)$ \\
Intensive use (day and night) & $11(13.1)$
\end{tabular}

${ }^{*} 1$ participant did not provide this information.

tongue positioned on the floor of the mouth or between the arches when at rest, ogival- or deep-shaped hard palate, and atypical or adapted swallowing pattern. The proportion of children who were mouth breathers was higher among those with a pacifier-sucking habit than those without a pacifier-sucking habit. Eight of the 36 children with a pacifier-sucking habit $(22.2 \%)$ were predominantly mouth breathers, whereas only 4 of the 48 children without a pacifier-sucking habit (8.3\%) were predominantly mouth breathers.

The mean maxillary intercanine distance was significantly lower in children with a pacifier-sucking habit $(27.79 \mathrm{~mm})$ than in children without a pacifiersucking habit $(29.51 \mathrm{~mm} ; p<.0001)$. By contrast, the mean mandibular intercanine distance was similar in the two groups $(23.44 \mathrm{~mm})$.

The results of Poisson regression analysis of the occlusal and oral myofunctional variables significantly associated with a pacifier-sucking habit are presented in Tables 3 and 4, respectively. The likelihood of malocclusion was significantly increased with all durations and frequencies of pacifier use, with a prevalence ratio (PR) of 2.33 in children with a pacifiersucking habit compared to children without a pacifiersucking habit $(p<.001)$. In general, all components of malocclusion tended to be more affected by the duration of pacifier-sucking habit than by the frequency 
Table 2. Prevalence of dental occlusion and oral myofunction alterations.

\begin{tabular}{|c|c|c|c|c|c|}
\hline $\begin{array}{l}\text { Dental Occlusion } \\
\text { Alteration }\end{array}$ & Pacifier Use n (\%) & No Pacifier Use n (\%) & $\begin{array}{c}\text { Oral Myofunction } \\
\text { Alteration }\end{array}$ & Pacifier Use n (\%) & No Pacifier Use n (\%) \\
\hline *Malocclusion & $27(77.8)$ & $16(33.3)$ & Asymmetric cheeks & $26(72.2)$ & $37(77.1)$ \\
\hline Midline deviation & $13(36.1)$ & $17(35.4)$ & $\begin{array}{c}\text { *Atypical tongue } \\
\text { position at rest }\end{array}$ & $14(38.9)$ & 9 (18.8) \\
\hline $\begin{array}{l}\text { *Altered canine rela- } \\
\text { tion on at least one } \\
\text { side (Class II or III) }\end{array}$ & $19(52.8)$ & $10(20.8)$ & $\begin{array}{l}\text { *Atypical swallowing } \\
\text { pattern }\end{array}$ & $10(27.8)$ & $10(20.8)$ \\
\hline *Increased overiet & $14(38.9)$ & $7(14.6)$ & $\begin{array}{l}\text { *Atypical hard palate } \\
\text { shape }\end{array}$ & $27(75.0)$ & $16(33.3)$ \\
\hline Overbite $>50 \%$ & $3(8.3)$ & $17(35.4)$ & $\begin{array}{c}\text { *Lips partially closed } \\
\text { at rest }\end{array}$ & $23(63.9)$ & $19(39.6)$ \\
\hline *Anterior open bite & $17(47.2)$ & $2(4.2)$ & $\begin{array}{l}\text { *Lips closed with } \\
\text { tension }\end{array}$ & $23(63.9)$ & $17(35.4)$ \\
\hline *Posterior crossbite & $10(27.8)$ & $3(6.3)$ & Atypical speech & 14 (38.9) & $20(41.7)$ \\
\hline \multirow[t]{3}{*}{ Anterior crossbite } & $1(2.8)$ & $2(4.2)$ & $\begin{array}{l}\text { Predominantly } \\
\text { unilateral chewing }\end{array}$ & $7(19.4)$ & $8(16.7)$ \\
\hline & & & $\begin{array}{l}\text { Short lingual } \\
\text { frenulum }\end{array}$ & $6(16.7)$ & 7 (14.6) \\
\hline & & & $\begin{array}{c}\text { Mouth breathing at } \\
\text { rest }\end{array}$ & $8(22.2)$ & $4(8.3)$ \\
\hline
\end{tabular}

*Significant difference between children with and without a pacifier-sucking habit (Chi-square test; $p<.05)$.

of pacifier use. Of all components of malocclusion, anterior open bite showed the strongest association with pacifier use $(\mathrm{PR}=11.33)$. The $\mathrm{PR}$ of anterior open bite increased with the frequency of pacifier use, but no clear pattern was observed for frequency of pacifier use with the other parameters studied.

The oral myofunctional alterations most significantly associated with a pacifier-sucking habit were altered shape of the hard palate $(\mathrm{PR}=1.29 ; p<.001)$ and altered swallowing pattern $(\mathrm{PR}=1.27 ; p<.001)$. With the exception of altered shape of the hard palate, which showed increasing PR with longer duration and higher frequency of pacifier use, no myofunctional alterations were associated with duration or frequency of pacifier use in a clear pattern. Therefore, the results indicate that oral myofunctional alterations are associated with a pacifier-sucking habit of any duration and frequency.

\section{Discussion}

Although several studies have been conducted on pacifier use and its consequences, this is the first to evaluate alterations in occlusion and oral myofunction in the same subjects. The data presented in this study confirm the association between prolonged pacifier use and alterations in occlusion and myofunction in young children.
Malocclusion was significantly associated with pacifier use, with a clear association between the presence of malocclusion and both the duration and frequency of pacifier use. Anterior open bite was the occlusal characteristic most affected by a pacifiersucking habit, with the likelihood of anterior open bite increasing with both duration and frequency of pacifier sucking, a finding that is in agreement with the results of previous studies. ${ }^{7,10,16,18}$ Other occlusal alterations significantly associated with pacifier use were posterior crossbite, altered canine relation, and increased overjet, with the likelihood of posterior crossbite significantly increased when the duration of the pacifier-sucking habit was more than 2 years. Similar associations have been reported in the literature. . $^{1,10,10,15}$

With a long duration and high frequency of pacifier use, there is a tendency for hyperfunction of the buccinator muscle, which causes a deficiency in transverse growth. In addition, in the presence of a pacifier, the tongue is kept low in the mouth and does not exert pressure against the hard palate, and this can aggravate ogival palate problems and lead to posterior crossbite. ${ }^{2}$ The associations of pacifier use with altered intercanine relation and increased overjet shown by Poisson regression in this study have also been 
Table 3. Results of Poisson regression analysis of the association between pacifier use and the presence of dental occlusion alterations in preschool children.

\begin{tabular}{|c|c|c|c|c|c|}
\hline & $\begin{array}{c}\mathrm{AOB} \\
\text { PR }(95 \% \mathrm{Cl})\end{array}$ & $\begin{array}{c}\text { ICR } \\
\text { PR }(95 \% \mathrm{Cl})\end{array}$ & $\begin{array}{c}\text { PCB } \\
\text { PR }(95 \% \mathrm{Cl})\end{array}$ & $\begin{array}{c}\text { OJ } \\
\text { PR }(95 \% \mathrm{Cl})\end{array}$ & $\begin{array}{c}M O \\
\text { PR }(95 \% \mathrm{Cl})\end{array}$ \\
\hline \multicolumn{6}{|l|}{ Use } \\
\hline No & 1.00 & 1.00 & 1.00 & 1.00 & 1.00 \\
\hline Yes & $11.33^{* * *}(2.79-45.95)$ & $2.53^{* *}(1.34-4.76)$ & $4.44^{*}(1.31-14.98)$ & $2.66^{*}(1.20-5.92)$ & $2.33^{* * *}(1.50-3.61)$ \\
\hline \multicolumn{6}{|l|}{ Duration } \\
\hline Never used & 1.00 & 1.00 & 1.00 & 1.00 & 1.00 \\
\hline$\leq 2$ years & $8.72 *(1.72-41.77)$ & $2.18(0.93-5.10)$ & $2.90(0.55-15.37)$ & $3.11^{*}(1.21-7.99)$ & $2.18^{* *}(1.27-3.74)$ \\
\hline$>2$ and $\leq 3$ & $10.66 * *(2.28-49.79)$ & $2.13(0.85-5.32)$ & $7.11^{* *}(1.90-26.53)$ & $1.51(0.37-6.18)$ & $2.33^{* *}(1.37-3.96)$ \\
\hline$>3$ years & $\begin{array}{c}14.40^{* * *} \\
(3.48-59.47)\end{array}$ & $\begin{array}{c}2.88^{* *} \\
(1.44-5.73)\end{array}$ & $\begin{array}{c}4.26^{*} \\
(1.07-16.96)\end{array}$ & $\begin{array}{c}3.20^{* *} \\
(1.33-7.65)\end{array}$ & $\begin{array}{c}2.40^{* * *} \\
(1.49-3.85)\end{array}$ \\
\hline \multicolumn{6}{|l|}{ Frequency } \\
\hline Never & 1.00 & 1.00 & 1.00 & 1.00 & 1.00 \\
\hline Limited & $5.53^{*}(1.03-29.74)$ & $1.84(0.76-4.45)$ & $6.15^{* *}(1.68-22.43)$ & $2.63^{*}(0.99-6.96)$ & $2.30^{* * *}(1.40-3.80)$ \\
\hline Moderate & $14.00^{* * *}(3.32-59.00)$ & $4.00^{* * *}(2.18-7.33)$ & $4.00(0.92-17.39)$ & $4.00^{* * *}(1.73-9.22)$ & $2.50^{* * *}(1.55-4.01)$ \\
\hline Intense & $15.27^{* * *}(3.66-63.71)$ & $1.74(0.67-4.54)$ & $2.90(0.55-15.37)$ & $1.24(0.29-5.20)$ & $2.18^{* *}(1.27-3.74)$ \\
\hline
\end{tabular}

${ }^{*} p<.05{ }^{* *} p<.01 ;{ }^{* * *} p<.001$.

PR: prevalence ratio; $\mathrm{Cl}$ : confidence interval; $\mathrm{AOB}$ : anterior open bite; ICR: (altered intercanine OR intercanine) relation; PCB: posterior crossbite; OJ: (increased overjet OR overjet); $M O$ : malocclusion.

demonstrated with a pacifier-sucking habit duration longer than 3 years in previous studies. ${ }^{910}$ However, Larsson et al.$^{19}$ found no association between these variables. These conflicting results may be due to the fact that increased overjet is more strongly associated with finger sucking than with pacifier sucking., ${ }^{1,7}$

The results of the present study show that use of a pacifier was associated with reduced maxillary intercanine distance, supporting previous reports that use of a pacifier for longer than 3 years with a moderate frequency was associated with alterations in the shape of the hard palate. ${ }^{1,2,10,14}$ This may indicate that alterations in the shape of the hard palate are related to reduced intercanine distance and altered position of the tongue at rest. ${ }^{13,21,22}$ Transverse growth is affected not only by sucking habits but also by chewing and swallowing patterns. ${ }^{9}$ Therefore, even at a low frequency of pacifier use, there was a relation between posterior crossbite and inadequate swallowing.,21

Changes in swallowing pattern are associated with a prolonged pacifier-sucking habit, which delays maturation of the swallowing reflex, and with malocclusions such as anterior open bite and posterior crossbite. ${ }^{716,21,22}$ Mouth breathing or interference with nasal breathing may also affect craniofacial growth and the position of the teeth. ${ }^{9}$ The higher proportion of mouth breathers among pacifier users in the present study may be due to the fact that the altered position of the tongue in the mouth causes pacifier users to keep their mouth open and, consequently, develop a mouth-breathing pattern.

The fact that both occlusal and myofunctional characteristics were evaluated in this study offered the opportunity to observe how occlusal and myofunctional alterations were interdependent and how they were affected by different pacifier use patterns. Our results showed that occlusal and myofunctional alterations associated with pacifier use can be described as a sequence of events. Duration had a greater impact on occlusion and myofunction than did frequency of use, and there was often no clear pattern between frequency of pacifier use and alterations in occlusion and myofunction. The children studied all came from similar family and social backgrounds and the sample was therefore relatively homogenous, but the small number of children studied was a limitation of this study. A larger sample size may have enabled us to establish a clear pattern between alterations in occlusion and myofunction and the duration and frequency of pacifier use. Another possible limitation is the reliability of the 
Table 4. Results of Poisson regression analysis of the association between pacifier use and the presence of oral myofunction alterations in preschool children

\begin{tabular}{|c|c|c|c|c|c|}
\hline & $\begin{array}{c}\text { LR } \\
\text { PR }(95 \% \mathrm{Cl})\end{array}$ & $\begin{array}{c}\mathrm{LO} \\
\text { PR }(95 \% \mathrm{Cl})\end{array}$ & $\begin{array}{c}\text { TR } \\
\text { PR }(95 \% \mathrm{Cl})\end{array}$ & $\begin{array}{c}\text { SHP } \\
\text { PR }(95 \% \mathrm{Cl})\end{array}$ & $\begin{array}{c}\text { SW } \\
\text { PR }(95 \% \mathrm{Cl})\end{array}$ \\
\hline \multicolumn{6}{|l|}{ Use } \\
\hline No & 1.00 & 1.00 & 1.00 & 1.00 & 1.00 \\
\hline Yes & $1.17^{*}(1.02-1.35)$ & $1.21^{* *}(1.05-1.39)$ & $1.15^{* *}(1.03-1.29)$ & $1.29^{* * *}(1.14-1.47)$ & $1.27^{* * *}(1.14-1.43)$ \\
\hline \multicolumn{6}{|l|}{ Duration } \\
\hline Never used & 1.00 & 1.00 & 1.00 & 1.00 & 1.00 \\
\hline$\leq 2$ years & $1.17(0.96-1.43)$ & $1.28^{* *}(1.06-1.53)$ & $1.20^{* *}(1.06-1.36)$ & $1.28^{* *}(1.06-1.53)$ & $1.37^{* * *}(1.24-1.51)$ \\
\hline$>2$ and $\leq 3$ years & $1.11(0.89-1.40)$ & $1.15(0.91-1.45)$ & $1.05(0.85-1.29)$ & $1.31^{* *}(1.09-1.58)$ & $1.21^{*}(1.01-1.46)$ \\
\hline$>3$ years & $1.19^{*}(1.00-1.42)$ & $1.18(0.98-1.42)$ & $1.17^{*}(1.03-1.33)$ & $1.33^{* * *}(1.14-1.55)$ & $1.21^{* * *}(1.01-1.46)$ \\
\hline \multicolumn{6}{|l|}{ Frequency } \\
\hline Never & 1.00 & 1.00 & 1.00 & 1.00 & 1.00 \\
\hline Limited & $1.21^{*}(1.01-1.45)$ & $1.19(0.99-1.45)$ & $1.66^{*}(1.01-1.33)$ & 1.19 (0.99-1.45) & $1.31^{* * *}(1.16-1.49)$ \\
\hline Moderate & $1.25^{* *}(1.06-1.49)$ & $1.29^{* *}(1.09-1.54)$ & $1.21^{* *}(1.07-1.36)$ & $1.35^{* * *}(1.16-1.58)$ & $1.20^{*}(1.01-1.42)$ \\
\hline Intense & $1.04(0.83-1.31)$ & $1.14(0.92-1.42)$ & $1.09(0.91-1.30)$ & $1.34^{* * *}(1.14-1.58)$ & $1.30^{* * *}(1.14-1.49)$ \\
\hline
\end{tabular}

${ }^{*} p<.05 ;{ }^{* *} p<.01 ;{ }^{* * *} p<.001$.

PR: prevalence ratio; Cl: confidence interval; LR: altered lip position at rest; LO: lips occluded; TR: altered tongue position at rest; SHP: altered shape of the hard palate; SW: altered swallowing.

information provided by caregivers. However, care was taken to obtain accurate information from caregivers, and we believe that the data obtained give an accurate reflection of pacifier use. Studies on non-nutritive sucking habits are broad in scope, with factors such as facial growth and breast- and bottle-feeding patterns being taken into consideration, and longitudinal studies that record pacifier use from infancy to early childhood are needed for a better understanding of the dynamics of occlusal and oral myofunctional alterations.

\section{Conclusion}

The results of the present study emphasize the importance of recognizing early occlusal and myofunctional changes caused by a pacifier-sucking habit in young children. Dentists working with young children must be aware of the association of pacifier use with occlusal and myofunctional characteristics and advise parents and caregivers of the risks involved in the prolonged use of pacifiers. Recommendations for the progressive discontinuation of pacifier use should be provided until the sucking habit ceases completely and should be tailored to each child's individual circumstance. Moreover, whenever necessary, multidisciplinary assistance should be recommended to minimize major irreversible deleterious effects of pacifier use.

\section{Acknowledgements}

The authors would like to thank Mr. Antonio Carlos Correa for his contribution with the English version of this paper; the Coordenação de Aperfeiçoamento de Pessoal de Nivel Superior - CAPES for the scholarship and the financial support; and the Nucleus of Dynamic in Oral Health $(\mathrm{NuDOH})$ for the substantiation of this study through the congregation of ideas. 


\section{References}

1. Bishara SE, Warren JJ, Broffit B, Levy S. Changes in the prevalence of nonnutritive sucking patterns in the first 8 years of life. Am J Orthod Dentofacial Orthop. 2006 Jul;130(1):31-6.

2. Larsson E. Prevalence of crossbite among children with prolonged dummy- and finger-sucking habit. Swed Dent J. 1983;7(3):115-9.

3. Larsson E, Dhalin K. The prevalence and etiology of the initial dummy and finger sucking habit. Am J Orthod. 1985 May;87(5):432-5.

4. Levine RS. Briefing paper: oral aspects of dummy and digit sucking. Br Dent J. 1999 Feb 13;186(3):108.

5. Feldens CA, Ardenghi TM, Cruz LN, Scalco GPC, Vítolo MR. Advising mothers about breastfeeding and weaning reduced pacifier use in the first year of life: a randomized trial. Community Dent Oral Epidemiol. 2013 Aug;41(4):317-26.

6. Romero CC, Scavone-Junior H, Garib DG, Cotrim-Ferreira FA, Ferreira RI. Breastfeeding and non-nutritive sucking patterns related to the prevalence of anterior open bite in primary dentition. J Appl Oral Sci. 2011 Apr;19(2):161-8.

7. Silva Filho OG, Santamaria Jr M, Capelozza Filho L. Epidemiology of posterior crossbite in the primary dentition. J Clin Pediatr Dent. 2007 Fall;32(1):73-8.

8. Duncan K, McNamara C, Ireland AJ, Sandy JR. Sucking habits in childhood and the effects on the primary dentition: findings of the Avon longitudinal study of pregnancy and childhood. Int J Paediatr Dent. 2008 May;18(3):178-88.

9. Warren JJ, Bishara SE, Steinbock KL, Yonezu T, Nowak AJ. Effects of oral habits' duration on dental characteristics in the primary dentition. J Am Dent Assoc. 2001 Dec;132(12):1685-93.

10. Warren JJ, Bishara SE. Duration of nutritive and nonnutritive sucking behaviors and their effects on the dental arches in the primary dentition. Am J Orthod Dentofacial Orthop. 2002 Apr;121(4):347-56.

11. Heimer MV, Tornisiello Katz CR, Rosenblatt A. Non-nutritive sucking habits, dental malocclusions, and facial morphology in Brazilian children: a longitudinal study. Eur J Orthod. 2008 Dec;30(6):580-5.

12. Vasconcelos FM, Massoni AC, Heimer MV, Ferreira AMB, Katz CR, Rosenblatt A. Non-nutritive sucking habits, anterior open bite and associated factors in Brazilian children 30-59 months. Bras Dent J. 2011;22(2):140-5.

13. Larsson E. Sucking, chewing, and feeding habits and the development of crossbite: a longitudinal study of girls from birth to 3 years of age. Angle Orthod. 2001 Apr;71(2):116-9.

14. Scavone-Junior H, Ferreira RI, Mendes TE, Ferreira FV. Prevalence of posterior crossbite among pacifier users: a study in the deciduous dentition. Braz Oral Res. 2007 AprJun;21(2):153-8.

15. Melink S, Vagner MV, Hocevar-Boltezar I, Ovsenik M. Posterior crossbite in the deciduous dentition period, its relation with sucking habits, irregular orofacial functions, and otolaryngological findings. Am J Orthod Dentofacial Orthop. 2010 Jul;138(1):32-40.

16. Verrastro AP, Stefani FM, Rodrigues CR, Wanderley MT. Occlusal and orofacial myofunctional evaluation in children with primary dentition, anterior open bite and pacifier sucking habit. Int J Orofacial Myology. 2006 Nov;32:7-21.

17. Zardetto CG, Rodrigues CR, Stefani FM. Effects of different pacifiers on the primary dentition and oral myofunctional structures of preschool children. Pediatr Dent. 2002 Nov-Dec;24(6):552-60.

18. Katz CR, Rosenblatt A, Gondim PPC. Non-nutritive sucking habits in Brazilian children: effects on deciduous dentition and relationship with facial morphology. Am J Orthod Dentofacial Orthop. 2004 Jul;126(1):53-7.

19. Larsson E, Ogaard B, Lindsten R. Dummy- and finger -sucking habits in young Swedish and Norwegian children. Scand J Dent Res. 1992 Oct;100(5):292-5.

20. Korbmacher HM, Schwan M, Berndsen S, Bull J, Kahl-Nieke B. Evaluation of a new concept of myofunctional therapy in children. Int J Orofacial Myology. 2004 Nov;30:39-52.

21. Marchesan IQ, Krakauer LR. The importance of respiratory activity in myofunctional therapy. Int J Orofacial Myology. 1996 Nov;22:23-7.

22. Akin E, Sayin MO, Karaçay S, Bulakbasi N. Real-time balanced turbo field echo cine-magnetic resonance imaging evaluation of tongue movements during deglutition in subjects with anterior open bite. Am J Orthod Dentofacial Orthop. 2006 Jan;129(1):24-8. 